\title{
Care for Psychiatric Patients that Use Drugs: Management and Perceptions of Professionals ${ }^{1}$
}

\author{
Eduardo Augusto Leão ${ }^{2}$, Clarissa Mendonça Corradi-Webster ${ }^{2}$ \\ ${ }^{2}$ Universidade de São Paulo, Ribeirão Preto-SP, Brazil
}

\begin{abstract}
There is a high prevalence of drug use among psychiatric patients, favoring worse prognosis and situations of vulnerability. The aim of this study was to understand the perception and management of mental health professionals related to the use of drugs among people receiving psychiatric care. Semi-structured interviews were conducted with 16 professionals. Through thematic analysis, three categories were constructed: (1) Identification of drug use, performed with some difficulty through self-reports, collected by doctors and nursing assistants, being the essential link; (2) Actions taken to manage drug use situations, focusing on abstinence counseling and many referrals; (3) Presence of moral discourses in the care offered. The team reports difficulties in dealing with situations of drug use among patients, from identification to management. The different ways of dealing with consumption were related to how the professional understands the use of drugs.
\end{abstract}

Keywords: psychiatric patients, drug (use), health professionals

\section{Uso de Drogas por Pessoas em Tratamento Psiquiátrico: Manejo e Percepção dos Profissionais}

\begin{abstract}
Resumo: Há alta prevalência de consumo de drogas entre pacientes psiquiátricos, favorecendo pior prognóstico e situações de vulnerabilidade. O objetivo deste estudo é compreender a percepção e o manejo de profissionais de saúde mental sobre o uso de drogas entre pessoas em tratamento psiquiátrico. Foram realizadas entrevistas semiestruturadas com 16 profissionais. Foram construídas três categorias a partir de análise temática: (1) Identificação do uso de drogas, realizada com certa dificuldade por meio de autorrelato colhido por médicos e auxiliares de enfermagem, destacando-se o vínculo como essencial; (2) Ações realizadas para manejar situações de uso de drogas, focadas na orientação para abstinência e resultando em muitos encaminhamentos; (3) Presença de discursos morais no cuidado oferecido. A equipe relata dificuldades para lidar com situações de consumo de drogas relatadas pelos pacientes, desde a identificação até o manejo. As diferentes formas de lidar com o consumo mostram-se relacionadas ao modo como o profissional de saúde mental compreende o uso de drogas.
\end{abstract}

Palavras-chave: pacientes psiquiátricos, droga (uso), profissionais da saúde

\section{Uso de Drogas por Personas en Tratamiento Psiquiátrico: Percepción y Acompañamiento de los Profesionales}

\begin{abstract}
Resumen: Hay alta prevalencia de consumo de drogas entre pacientes psiquiátricos, favoreciendo peor pronóstico y situaciones de vulnerabilidad. El objetivo de este estudio es comprender la percepción y el manejo de profesionales de salud mental sobre el uso de drogas entre personas en tratamiento psiquiátrico. Se realizaron entrevistas semiestructuradas con 16 profesionales. Con análisis temático se construyeron tres categorías: (1) Identificación del uso de drogas, realizada con cierta dificultad por medio de autorrelato recogido por médicos y auxiliares de enfermería, destacándose el vínculo como esencial; (2) Acciones realizadas para manejar situaciones de uso de drogas, siendo éstas enfocadas en la orientación hacia abstinencia y ocurriendo muchos encaminamientos; (3) Presencia de los discursos morales en el cuidado ofrecido. El equipo relata dificultades para lidiar con situaciones de consumo de drogas entre los pacientes, desde la identificación hasta el manejo. Las diferentes formas de lidiar con el consumo se muestran relacionadas con el modo en que el profesional de salud mental comprende el uso de drogas.
\end{abstract}

Palabras clave: pacientes psiquiátricos, drogas (uso), profesionales de la salud

\footnotetext{
'Support: National Council for Scientific and Technological Development (CNPQ; Grant \# 449623/2014-9).

Correspondence address: Clarissa Mendonça Corradi-Webster. Universidade de São Paulo. Faculdade de Filosofia, Ciências e Letras de Ribeirão Preto. Departamento de Psicologia. Avenida Bandeirantes, 3900, Ribeirão PretoSP, Brazil. CEP 14.040-901. E-mail: clarissac@usp.br
}

The use of substances by people with psychiatric diagnoses is highlighted in the literature as becoming increasingly prevalent (Hamilton, 2010; Schlosser \& Hoffer, 2012). A survey carried out among psychiatric inpatients found that $12 \%$ consumed alcohol and 28\% used illicit drugs (Mordal et al., 2011). 
A study conducted in two community mental health services identified that $13.6 \%$ of the participants presented problematic consumption of alcohol and 9\% of illicit drugs (CorradiWebster \& Gherardi-Donato, 2016).

Drug use can affect people with a psychiatric condition in several ways, and is related to increased symptoms (Nehlin, Fredriksson, \& Jansson, 2012), homelessness, risk behaviors, crime, and a decrease adherence to medication. These factors can lead to a greater need for use of mental health services and psychiatric hospitalizations (Mordal et al., 2011; Ostacher et al., 2010). For Williamson, Johnson, Mullen and Wilson (2012) one of the factors causing the "revolving door" effect in mental health services is the use of drugs by people with psychiatric conditions.

Faced with this problem, the identification of drug use among users of mental health services is essential for the adequacy of treatment plans. However, this identification is still underestimated in the services (Corradi-Webster, Laprega, \& Furtado, 2009) and among the reasons for this are the fear of patients being stigmatized by the team and the fear of admitting consumption of a drug considered illicit (Hamilton, 2010). For Corradi-Webster (2013) patients also fear that when addressing this issue they will be referred to specialized services in the treatment of problems related to drug use and lose the link with the mental health service in which they are being monitored. Vieira (2016) observed that mental health services tend to refer all individuals who use illicit drugs to specialized services, regardless of consumption pattern, impairing the link and the relationship of trust between drug user and professional, increasing cases of underreporting. The limited time available to professionals for the complete evaluation and diagnosis also seems to contribute to the non-identification (Corradi-Webster et al., 2009) or to the professional having difficulty correctly evaluating the consumption pattern and the impact of this on the individual, resorting to referral even in situations of sporadic and/or recreational use (Vieira, 2016). Szerman et al. (2014) suggest that mental health teams address this issue in an way that is integrated to the service procedures.

The literature has named "comorbidity" the situations in which one or more disorders are identified in the same individual. However, there is a diversity of understandings and a difficulty in defining what comorbidity is, impacting on identification and treatment (Morojele, Saban, \& Seedat, 2012). If it is understood as two independent conditions, with distinct clinical courses, a strict separation between mental health services and specialized services for the use of substances is justified (Schuckit, 2006). However, Krueger and Markon (2006) emphasize that a person who fulfills criteria for a specific mental disorder is more likely to meet criteria for another disorder, indicating that the different constructs named as mental disorders are correlated. For the authors, nosological categories would share the same susceptibilities, being only alternative manifestations. They suggest that treatment should focus on these susceptibilities and point out personality traits as aspects that would be common in different disorders.
Another explanatory model for comorbidity is that one clinical picture would influence the development of the other, as in situations in which drug use aims self-medication (Nehlin et al., 2012). Drug use would be a way to deal with some symptoms and also with side effects of psychotropic medications (Hamilton, 2010). A study with patients with schizophrenia that used marijuana identified that, despite an increase in positive symptoms, many continued to consume the substance because they considered it to help control auditory hallucinations as well as decrease anxiety and insomnia (Costain, 2008). The lack of space to talk about the effects and autonomous management of psychotropic drugs (Onocko-Campos et al., 2013) can also contribute to the individual seeking from the drug use a way of dealing with undesirable side effects.

One of the difficulties of the therapeutic approach in cases of substance use by people with psychiatric disorders is due to the existing division between services, hindering the diagnostic evaluations that investigating the presence of drug use in patients in mental health services, disrupting comprehensive care (Silva, Kolling, Carvalho, Cunha, \& Kristensen, 2009). Services specialized in comorbidities are incipient and not always recommended, with the suggestion that mental health teams approach this issue in a way that is integrated to the service procedures (Szerman, et al., 2014). In addition, many people receiving psychiatric treatment and who consume drugs do not meet criteria for substance use disorders, because they use drugs in a recreational or sporadic way, and referral to specialized drug services is not justified (Vieira, 2016).

Hamilton (2010) highlights the need for action in the area that takes into account the patients' point of view, helping them plan changes in their lifestyles, acquiring and improving social bonds, rather than just focusing on outcomes related to symptomatology. Corradi-Webster and Gherardi-Donato (2016) recommend that mental health services value psychosocial actions, seeking to investigate the patients' social support network, their modes of socialization and financial needs, since the use of substances may be related to these issues.

Considering the high prevalence of drug use among psychiatric patients, the existing division in the care network between mental health services and services targeting drug users and the need to provide integral assistance, it is necessary to investigate how drug use situations are managed in mental health services, in order to identify fragilities that need to be remedied and resources that can be disseminated among services. Therefore, the aim of this study was to understand the perception and management by mental health professionals regarding the use of drugs among people receiving psychiatric treatment.

\section{Method}

A study with a qualitative, descriptive and experiential design, aiming to validate meanings, perspectives and practices in the constructed corpus, focusing and prioritizing the interpretations made by the participants, without using them as a basis for other theoretical interpretations (Braun \& Clarke, 2014). 


\section{Participants}

A total of 16 professionals participated in this study of a community mental health service in a medium-sized municipality in the state of São Paulo, Brazil. All the employees who were part of the morning team (07:00 to 13:00) were invited to participate. This period was selected due to focusing most of the team and service activities. The inclusion criteria were: (a) to be part of the fixed team of the selected service, working at least once a week in the morning; (b) to have worked in the position for at least six months; and (c) to have contact at the service level with the service users. Regarding gender, seven men and nine women participated. Considering the professional category, three psychiatrists, one nurse, one pharmacist, three psychologists, a social worker, an occupational therapist, five nursing technicians nd an administrative technician participated.

\section{Instruments}

The instrument used was the semi-structured interview script, elaborated based on the objective of the study. This instrument allows the researcher to have a script with questions that need to be addressed, with a space for other topics to be brought by the interviewer, considering the words used, the orders of the questions and the deepening given to the theme adapted to the context and report of the patient (Braun \& Clarke, 2014). In order to better understand the interviewee, the script was initially composed of questions about professional training and working time at the institution, followed by questions that sought to investigate how the professional understood drug use and the user. Afterwards, questions were focused on the theme studied, seeking to investigate how the professionals understood the use of drugs by people with psychiatric disorders, how these situations appeared and were managed in the service where they worked and how they felt they could contribute to dealing with these cases.

\section{Procedure}

Data collection. The study proposal was presented at the service team meeting and doubts about the intention and procedures of the study were answered. Professionals who fulfilled the inclusion criteria were individually invited to participate in the study and the interviews were scheduled individually. Fifteen participants chose to perform the interview in the service studied, in rooms used for the consultations, and only one of them preferred that it be performed in their private practice, due to the lack of time during their work in the service. The collection was carried out in the first half of 2014. All interviews were audio-taped and the corpus consisted of 15 hours and 35 minutes of interviews, with the average time of each one being 57 minutes.

Data analysis. Thematic analysis was carried out according to Braun and Clarke (2006). The analysis was conducted in six phases: (1) Familiarization with the data through the complete transcription of interviews and readings; (2) Construction of initial codes, identifying statements that were relevant to the purpose of the study and codifying what they were about; (3) Construction of themes through the organization of the codes; (4) Review of the themes, seeking to investigate how these were related to the initial codes and data as a whole and production of thematic maps; (5) Definition and naming of themes; (6) Production of the final report through the selection of extracts that illustrated the topics and the discussion of the results considering the literature of the area. Steps 2, 3, 4 and 5 were performed separately by the two authors of this paper and the final results were negotiated between them.

\section{Ethical Considerations}

The project was approved by the Ethics Committee for Research with Human Subjects (CAAE 20875913.6.0000.5407). All participants read and signed the consent form. Seeking to preserve the identities of the interviewees, in the transcription of the statements, all were treated as being of the masculine gender.

\section{Results and Discussion}

After analyzing the thematic content, the data were organized into three themes: Identification of drug use in service patients; Actions taken in the mental health service to deal with drug use situations; Presence of moral discourses in the care offered.

\section{Identification of Drug Use in Patients in the Service}

For the professionals, many patients seen in the mental health service consume drugs and they consider that this consumption produces numerous unfoldings in the treatment of these people, with the need for identification being urgent. In this theme. the resources and difficulties that were listed to carry out this evaluation will be described. Figure 1 summarizes the theme.

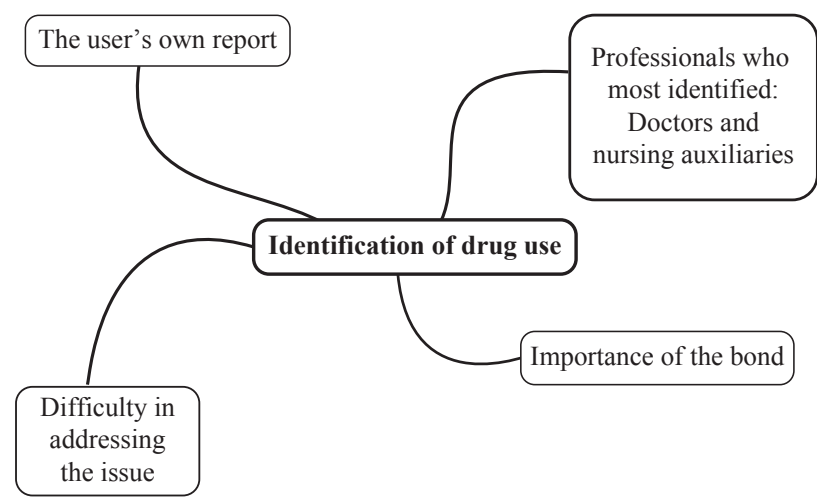

Figure 1. Identification of drug use in service patients. 
Despite the importance attributed to the identification of drug use, analysis of the corpus indicated that there is no protocol for its implementation. Several professionals mentioned the importance of this evaluation, either to provide more adequate care within the service, or to consider the referral of these patients for treatment in other services of the network. The identification of drug use is usually done from the user's own report; however, this type of report does not seem to be so easily obtained. Participant P2 pointed out that the patient does not talk about drug use at first, sometimes lying or omitting his/her consumption in their report to the team: "I actively ask, what is the frequency, what drug do you use, and even if they initially lie, in the end they end up talking".

Although the survey has emerged as the main strategy of professionals to identify drug use, it has not proved to be a simple process to implement because of the stigma attached to the use of these substances. The literature recommends that the evaluation of drug use can be performed through clinical interview, standardized instruments or toxicological tests (Mordal et al., 2011; Nehlin et al., 2012). In the statement of $P 2$ it was observed that more time spent on the evaluation can collaborate the report of the patient. However, professionals often do not have enough time to do an in-depth interview (Corradi-Webster et al., 2009). For this reason, Nehlin et al. (2012) argue that asking a single question about alcohol use would be more important than not addressing the issue at all. Another barrier found to collect the patient's report refers to the difficulty of some professionals in asking questions related to drug use. The statement of P5 exemplifies this situation:

Sometimes yes (question about use), but not directly, because that offends, so I try to ask 'And then, is there anything different?' The person himself speaks 'No, no, I do not use drugs, I do not use drugs anymore'. Sometimes I say, 'Oh, is everything okay?', 'Did something different happen?', 'Did you do anything different?' They say, 'No, no, I'm not using drugs anymore'.

In this statement it can be noticed that the professional did not consider the evaluation of the use of drugs to be a health issue, since he worried about offending the patient when asking about the subject. He treated the issue as if it was something intimate, and thus the bond becomes essential for the conversation to take place. Therefore, it would require some time and also effort of the professional in constructing a favorable atmosphere for the report.

Some professionals were listed as being in a privileged situation to collect the patient's report. For the interviewees, the contact in the medical consultation would invite more confidential moments, because they are held in closed rooms and at scheduled times, in addition to a more directive posture of the medical professional, investigating several areas of the patient's life. These factors could contribute to the identification, as described by P9: "And we may suspect or not, but independently, the person will undergo the evaluation of the doctor and the doctor identifies this quickly".

The nursing team was also listed as important in this evaluation. These professionals meet with patients in structured therapeutic activities and also in the corridors, participate in lunch together, as well as perform shifts on weekends and in the afternoon and evening. This contact seems to enable a consistent link between professional and patient, establishing a relationship of care and trust, in order to obtain important information for the construction of the therapeutic project. Participant P9 emphasized that nursing auxiliaries would be better able to perceive and identify this use of drugs within the service: "auxiliaries are the ones who perceive the most, because they live with that person more, the coexistence is much more intense". As this topic seems difficult to talk about, the bond would help the patient to feel more willing to report on consumption (Nehlin et al., 2012).

For Hamilton (2010) the nursing team plays a fundamental role in the detection of substance use in patients diagnosed with mental disorders and they should be alert to the signs. However, Vieira, Caldana and Corradi-Webster (2013) reported that, despite the physical proximity of nursing auxiliaries and patients favoring a deepening of the bond between them, there is still a great prejudice in relation to mental health service patients who use drugs, which could impair therapeutic actions. These professionals have experiences with mental health, however, working with people who also use drugs requires a change in their practices, which involves not only agreeing that old practices need to be reviewed, but also constructing new ones, something that cannot be done fast and linearly (Brousselle, Lamothe, Sylvain, Foro, \& Perreault, 2010).

\section{Actions Performed in the Mental Health Service to Manage Drug Use Situations}

In this theme the actions that are carried out in the service to manage the situations in which the drug use presents itself were organized. Figure 2 illustrates how the different actions reported are based on the professionals' understanding about the reasons for drug use and also their views on what the treatment in mental health should be.

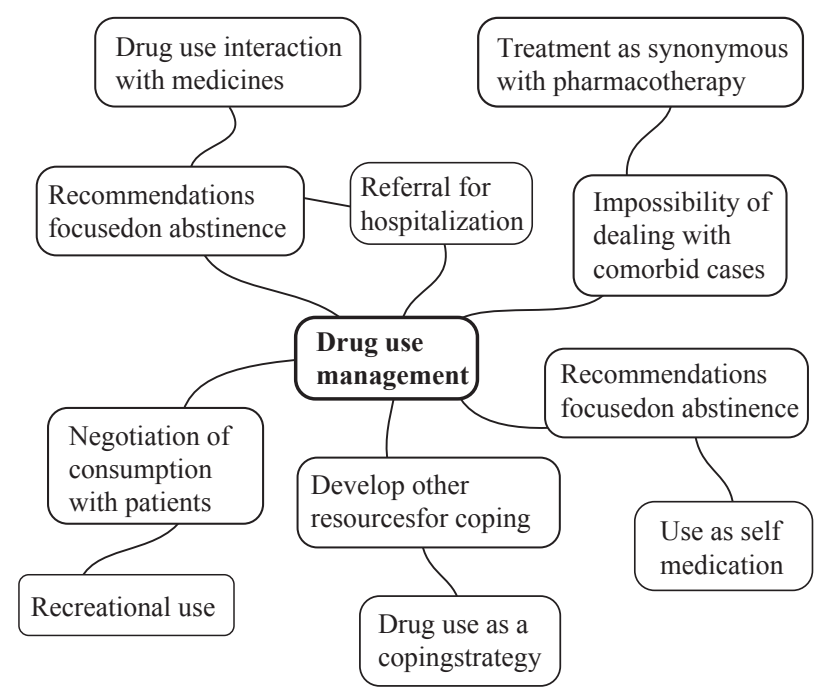

Figure 2. Actions taken in the service to handle situations of drug use. 
Practitioners consider the interaction between drug use and medicines to be dangerous and this argument is used to support the guideline that patients should entirely refrain from consuming other substances. This is observed in the statement of P5:

Some medicines, most of them are like that, they suffer interaction with alcohol, in fact I think $90 \%, .$. You will have the interactions and depending on the quantity, it can lead to coma... then it cannot happen at all.

For Onocko-Campos et al. (2013), although there are different care tools in the context of community mental health services, the central role attributed to medication makes regular use of the medicine synonymous with treatment, often leading to the understanding that if the patient does not use the medication as it has been prescribed he is resisting treatment and should not continue in the service. This helps to understand the difficulty of professionals dealing with situations in which patients also consume recreational drugs. If the medicine use is seen as central to the treatment and, as highlighted in P5's statement, the medicine's interaction with drugs is considered to always be very dangerous, it is difficult to think of ways to care for people who have psychiatric disorders and use drugs. The statement of P3 illustrates this difficulty: "The psychiatric patient, who makes use of drugs, there is no way to treat such a patient. You give him medicine and he continues using drugs. I mean, you're potentialzing the drug, potentializing alcohol. There's no way to handle it".

Since they do not see possibilities of treatment in the mental health service for people who are using any drug, the professionals focus on the importance of abstinence, as a criterion so that they can continue the service. Participant P9 addressed this question: "Ideally, he should not stay here, at least as long as he's using it. Now, if he is in treatment, in abstinence, there it is okay". The referral for hospitalization is understood as the solution to these situations, since this would be the therapeutic resource that would make it possible to keep the person away from drug use. This can be illustrated in the statement of P2: "and we have to keep the person hospitalized, and it is not three months, a year! It's a fairly long hospital stay".

Some possibilities of negotiation are proposed when they understand that the consumption of drugs is something recreational. For P5, even considering the use of medications as a synonym for treatment and being concerned about the interaction between these medicines and alcohol, it was necessary to negotiate with patients and provide harm reduction guidelines, thus ensuring continuity in the treatment.

So now if you're going to talk to a patient like E., she likes to drink a beer, she takes sertraline and clonazepam, what I told her was about using alcohol and clonazepam, which can be dangerous, but she cannot stop taking the medicine . .
Then she cannot be without the medicine and she used to stop taking the medicines, because she wants to drink a little, then talking to her and the amount she said she drinks, it does not interfere with her medications so much, so it is better that she take the medicines clonazepam and carbamazepine and at night if she wants a little beer okay, but only on Saturday, which was agreed. Its better to talk like that than to tell her that she cannot ever drink, if I said that, she'll drop the treatment, she will not quit drinking the beer on Saturday night.

An attempt of negotiation between professional and patient can be observed in this statement. Even considering that abstinence would be more appropriate, the professional sought to investigate the habits of the patient and took them into account when providing the guidelines. Schlosser and Hoffer (2012) emphasize the importance of the team being aware that often the patient of mental health services who uses drugs will continue to consume them during psychiatric treatment, not basing their practices on the illusion of complete abstinence.

In some situations the professionals consider that the use of drugs appears as an attempt for self-medication of the individuals and observe how it develops rather than focusing a priori on the strategy of abstinence, as observed in the statement of P6.

A schizophrenic patient I attended smoked marijuana and marijuana made him very calm, so marijuana worked for him as an anxiolytic. Then he smoked marijuana and became relaxed, less distressed, less aggressive, less irritated ... And then? That's nice? This is bad? Is that right? Is that wrong? Should he stop? Should he continue? I do not know, I honestly do not know. So I do not know if for this patient the use of marijuana is bad . . . It may be necessary, so I try to have this posture, of not having a lot of prior conceptions, of trying to look at it, is it not worth it in this case to continue using?

Anguish can be perceived in the statement of P6 in relation to how to deal with the situation. On the one hand, still inconclusively, the literature reports that there seems to be a possible association between marijuana use in adolescence and the development of schizophrenia (Proal, Fleming, Galvez-Buccollini, \& DeLisi, 2014), and that this consumption may increase positive symptoms (Costain, 2008). On the other hand, patients report improvement in symptoms when consuming marijuana (Costain, 2008). In the case reported, the professional interviewed chose not to focus on abstinence and to observe the development of the framework, understanding that even knowing the risks, he should respect the way the patient had chosen to deal with his/her suffering. Strategies focused on harm reduction 
are still poorly disseminated to the population receiving treatment for mental disorders, since professionals focus on abstinence due to the interaction of drugs with medications and also for fear of worsening the clinical status. However, as many people continue to use drugs, these strategies also need to be developed in the area. In London, a booklet was published for practitioners and users, with guidelines on the use of marijuana by people with schizophrenia (Linnell \& Holland, 2007). This included guidelines on the effects of the substance, possible interactions with medications and how the user can see whether the consumption has harmed him, as well as tips for situations where he realizes that the effects of consumption are undesirable. The benefit of these interventions is that they open space for dialogue, since the professional goes beyond the guidance that the patient should not use the drug.

It was also observed that when there is an understanding of drug use as a strategy to confront unpleasant feelings and sensations, other therapeutic resources, in addition to abstinence guidelines, were mentioned. Participant P1 talked about the importance of helping the patient to develop better adapted confronting alternatives.

So I see people as defending themselves, using drugs they are trying to lessen the discomfort. I think that anyone who is using drugs needs a look at that need that is behind the drug. Can you organize this life so that you can sleep better?

In this situation, it was observed that possibilities for dialogue are amplified and that the professional takes responsibility for the patient, helping him to think of other strategies to manage stress situations.

\section{Presence of Moral Discourses in Care}

This topic discusses how moral discourses influence the positions taken by the professionals when faced with the use of drugs by users of mental health services. Figure 3 graphically presents the unfolding results of this discourse.

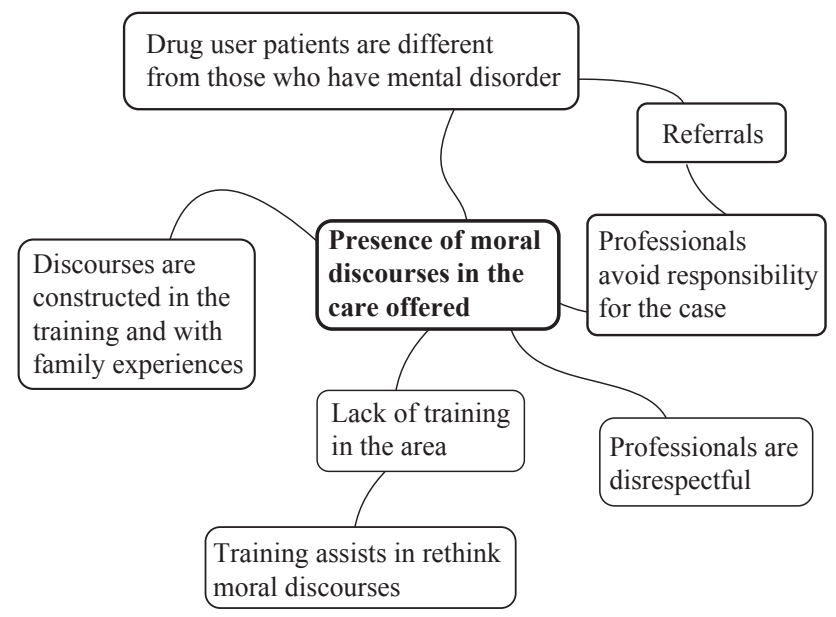

Figure 3. Presence of moral discourses in the care offered.
While the psychiatric disorder is understood as something that victimizes the individual, drug use is perceived as an option, making it difficult for the professional to empathize with the patient's suffering. This can be seen in the statement of P14:

I'm totally against it. I think I have a very large defect, that I cannot view a psychiatric patient, who had an outbreak, has a problem, and who is sick by drug use in the same way. The chemically dependent patient. So I cannot have the same view, the patient that is having a crisis, I think he did not choose that, it happened, while the patient who is having a crisis due to drinking, or who became dependent on chemicals for some reason, he sought it out.

Vieira et al. (2013) interviewed nursing auxiliaries who had worked in a psychiatric hospital for many years and reported that they had recently received cases of comorbidity. They observed that they had many difficulties in accepting drug users as people who also needed care. The view of drug use as a moral problem differentiates the patient with comorbidities from the non-drug user. The user is called shameless and someone who does not deserve health care. For Goffman (1988) the stigma is like a mark that accompanies certain groups, signaling that they should be avoided or marginalized. Ronzani, Noto and Silveira (2014) point out that stigma related to the drug user is a factor that hinders access and care of these people in health services, since users end up being identified as dangerous or irresponsible. Furthermore, for the authors, the stigma produces feelings of de-motivation in health professionals and distances them from the patients.

Moral discourses constructing meanings about drug use were reported as being present in the professional training, together with the lack of formal spaces for scientific discussion on the theme. The statement of participant P2 illustrates this situation:

I did not have chemical dependency training at my university. I see that it can be even a consequence of prejudice even though it was practically treated with disregard. You can understand that the bosses wanted to get rid of the patient who was dependent, and treated him as if he was a "thing", "shameless" and did not deserve care and that the other patients deserved it more.

It can be noted that the position adopted faced with the moral discourses is to "want to get rid of them quickly" to give attention to other patients who would be more deserving of care. When the service identified the use of drugs, the professionals were quite emphatic in claiming that they perceived the prejudice on the part of their colleagues of the team, often not taking responsibility for the patient, seeking to refer him to other services, as mentioned by P6. 
I think prejudice exists, when that person is identified as a user, people's views tend to change about that person. In addition, I think there is often a tendency to throw the problem into another sphere: 'Ah . . . is not it better to refer for hospitalization?', 'Ah . . . is it not better to refer to the drug service?

Personal and family experiences were also reported as influencing the posture adopted by the professionals. The use of drugs by relatives contributed to the professionals adopting the moral discourse (drug use as a personality problem and lack of will) to position themselves faced with this issue at work. The implication was the option of not getting involved in the care of people who used drugs and not talking about it with the patients. These constructions are always associated with statements of not being trained on the topic, as is illustrated in the statement of P7.

Due to having people in my family that abused drugs I always had a very great prejudice ... and I did not have much scientific training on this, but something more personal that they had no goodwill, that they did not want to treat themselves, boredom. So I've always put that as a limit on my training, I never wanted to work with people who had any issues with abusive use.

Moral discourses constructing meanings about drug consumption as a character problem are very widespread and limit the work of professionals, since they work within the field of health and not morality. Pillon and Luis (2004) highlighted that the moral discourse presents the use of drugs as the responsibility of the user, blaming them for not having the moral force to stop their use. The results of this study show how these discourses lead to the disinvestment of professionals in the mental health services.

Van Boekel, Brouwers, van Weeghel and Garretsen (2013) highlighted that, among the reasons that influence the negative attitudes of professionals towards the use of drugs by psychiatric patients, there is a perception that they do not have the necessary tools to promote care, generating demotivation and impacting on the professional's selfesteem. For Crapanzano, Vath and Fisher (2014), training for psychiatry professionals should have more space to discuss previous beliefs, as there may be difficulties in reconciling the understandings they already have about drug use with the new perspectives presented in the training. Participant P7 related how specific drug training helped him change his view: "I confess that I had a certain prejudice regarding abusive use of any drug, but I had a training course in mental health, crack, alcohol and drugs and I have to say, to confess, that I have undergone a radical change".

As previously mentioned, P7's posture on drug use was first influenced by family reports of the experience with a family member. The training in the use of drugs made it possible to construct new understandings about the subject, changing his posture and expanding the possibilities of action.

Despite the training in mental health, moral discourses influence how professionals relate to psychiatric patients who use drugs (Raitakari, Günther, Juhila, \& Saario, 2013). The problematic use of drugs is perceived as a failure of character and responsibility of the individual, leading to a disinvestment of the team and lack of responsibility. The stigma in this area is such an important factor that there are educational books that approach this issue with professionals. The guide for reducing stigma among drug users highlights the need to evaluate the human dimension of drug use, seeking to understand the relationship that each person establishes with consumption, and also draws attention to the importance of the therapeutic alliance for treatment success (Ronzani et al., 2014). As treatment in mental health services is still very focused on the use of medications and the interaction of these with recreational drugs can be harmful, the team feels without resources to deal with these people, seeking referral to other services. It is interesting to note that when professionals expand their understanding of drug use beyond the moral discourse and consider it as an attempt at self-medication or as a confronting resource, they construct possibilities for negotiation and dialogue with users, seeking to better understand the meanings of consumption for them, creating care alternatives.

Although the literature suggests the use of standardized instruments and toxicological tests, the analysis identified that the light technologies (Merhy, 2002) related to listening, bonding, welcoming and autonomization seem to be the strategies considered potent in the service to collect the patient's report on drug use and to construct care strategies with user and professional engagement.

It was identified that mental health training and work experience in the area do not seem to ensure that professionals feel empowered to deal with drug use issues among psychiatric patients. Conversely, more specific training related to the topic of drugs seems to help in the change of beliefs and postures of the professionals, helping them to become more involved with the case and to seek alternatives of care. Different forms of training have been proposed and studied, such as the use of the debate wheel technique in which the mediator uses a trigger to start the discussion on a given topic (Gallassi, Souza, \& Silva, 2016) or the development of collaborative projects among different professionals (Matta et al., 2016). In this sense, the fact that the participants did not mention any joint work with experts in the treatment of drugs draws attention. Alternatives such as shared care through discussions between mental health service teams and specialized services in alcohol and other drugs can also be promising in this area, however, it is necessary for professionals in both services to overcome barriers and recognize inherent limitations to their specialty, seeking to jointly discuss measures to be implemented case-by-case (Edward, Hearity, \& Felstead, 2012). Group therapeutic strategies carried out in mental health services for people who use drugs can also be effective because they 
provide a space to talk about these issues, leading to more awareness and management.

Knowing how care has been offered in mental health services helps to check for neuralgic points and to propose suggestions for overcoming them, as well as to identify the resources that have been used by the team, disseminating them as strategies to be tested by other teams. This study showed that light technologies are essential for the identification and management of drug use and that the moral view on consumption needs to be questioned so that professionals can be responsible for the care and negotiate strategies with those individuals under psychiatric treatment and who cannot or do not want to be abstinent.

From the reports of the participants, it was noted that, even though there is a division between mental health services and specialized drug services, many people undergoing treatment for psychiatric disorders also use drugs in different consumption patterns. The construction of spaces of conversation about how they see this consumption could reduce stigmas and bring the professional closer to the patient, strengthening bonds and enabling the construction of care strategies, refining the institution's discourses and enabling more coherent practices within the service.

This study described strategies used to identify and manage drug use among psychiatric patients, however, did not evaluate their effectiveness. It is suggested that future studies be conducted to evaluate these interventions. Another limit of this study was to have worked with all the interviews, without dividing them by professional category. Studies focusing on distinct professional categories may help to understand how the different formations influence the professional's view on the use of drugs by psychiatric patients and also on the possibilities for the care offered. However, the analysis presented here presents how a typical interdisciplinary team of community mental health services understands this subject.

\section{References}

Braun, V., \& Clarke, V. (2006). Using thematic analysis in psychology. Qualitative Research in Psychology, 3(2), 77-101. doi:10.1191/1478088706qp063oa

Braun, V., \& Clarke, V. (2013). Successful qualitative research: A practical guide for beginner. Thousand Oaks, CA: SAGE.

Brousselle, A., Lamothe, L., Sylvain, C., Foro, A., \& Perreault, M. (2010). Integrating services for patients with mental and substance use disorders: What matters? Health Care Management Review, 35(3), 212-223. doi:10.1097/HMR.0b013e3181d5b11c

Corradi-Webster, C. M. (2013). Consumo de drogas: Considerações sobre a clínica no contexto do SUS [Drug consumption: Clinical considerations in the Brazilian National Health System context]. Saúde \& Transformação Social, 4(2), 14-20. Retrieved from http://www.redalyc. org $/ \mathrm{html} / 2653 / 265328844004$
Corradi-Webster, C. M., \& Gherardi-Donato, E. C. S. (2016). Factors associated with problematic drug use among psychiatric outpatients. Revista Latino-Americana de Enfermagem, 24, e2815. doi:10.1590/1518-8345.1444.2815

Corradi-Webster, C. M., Laprega, M. R., \& Furtado, E. F. (2009). Residentes em psiquiatria têm documentado problemas relacionados ao álcool em pacientes ambulatoriais? [Do psychiatry residents document outpatients' alcohol problems?] Revista de Psiquiatria do Rio Grande do Sul, 31(3), 187-191. doi:10.1590/S0101-81082009000300008

Costain, W. F. (2008). The effects of cannabis abuse on the symptoms of schizophrenia: Patient perspectives. International Journal of Mental Health Nursing,17(4), 227-235. doi:10.1111/j.1447-0349.2008.00538.x

Crapanzano, K., Vath, R. J., \& Fisher, D. (2014). Reducing stigma towards substance users through an educational intervention: Harder than it looks. Academic Psychiatry, 38(4), 420-425. doi:10.1007/s40596-014-0067-1

Edward, K. L., Hearity, R. N., \& Felstead, B. (2012). Service integration for the dually diagnosed. Australian Journal of Primary Health, 18(1), 17-22. doi:10.1071/PY11031

Gallassi, A. D., Souza, C. I. C., \& Silva, M. N. R. M. O. (2016). O debate sobre álcool, crack e outras drogas na formação universitária e o papel dos profissionais da rede intersetorial em uma ação de educação em saúde [The debate on alcohol, crack and other drugs in the education and the role of the professionals of the intersectoral network in a health education action]. Pesquisas $e$ Práticas Psicossociais, 11(3), 623-636.

Goffman, E. (1988). Estigma: Notas sobre a manipulação da identidade deteriorada [Stigma: Notes on the management of spoiled identity] (M. Lambert, Trad., 4a ed.). Rio de Janeiro, RJ: LTC.

Hamilton, I. (2010). Ensuring integrated treatment for people with mental health and substance use problems. Nursing Times, 106(11), 12-15. Retrieved from https://www. nursingtimes.net/roles/mental-health-nurses/ensuringintegrated-treatment-for-people-with-mental-health-andsubstance-use-problems/5012894.article

Krueger, R. F., \& Markon, K. E. (2006). Reinterpreting comorbidity: A model-based approach to understanding and classifying psychopathology. Annual Review of Clinical Psychology, 2, 111-133. doi:10.1146/annurev.clinpsy.2.022305.095213

Linnell, M., \& Holland, M. (2007). Mental illness and cannabis: The story of David, the man with the transparent head. London, United Kingdom: Lifeline. 
Matta, A. N. B., Locatelli, D., Silva, E. A., Contreras, M. V., Bittencourt, B. A., \& Noto, A. R. (2016). Processos formativos em álcool e outras drogas para trabalhadores da rede pública do município de São Paulo: A experiência do CRR-DIMESAD-UNIFESP [Training courses on addiction issues to workers from the public sector of São Paulo city: The experience of CRR-DIMESAD-UNIFESP]. Pesquisas e Práticas Psicossociais, 11(3), 637-649.

Merhy, E. E. (2002). Saúde: A cartografia do trabalho vivo [Health: The cartography of living work] (3a ed., Saúde em Debate, No. 145). São Paulo, SP: Hucitec.

Mordal, J., Holm, B., Gossop, M., Romoren, M., Morland, J., \& Bramness, J. G. (2011). Psychoactive substance use among patients admitted to an acute psychiatric ward: Laboratory findings and associations with clinical characteristics. Nordic Journal of Psychiatry, 65(3), 208-215. doi:10.3109/08039488.2010.527014

Morojele, N. K., Saban, A., \& Seedat, S. (2012). Clinical presentations and diagnostic issues in dual diagnosis disorders. Current Opinion in Psychiatry, 25(3), 181-186. doi:10.1097/YCO.0b013e328351a429

Nehlin, C., Fredriksson, A., \& Jansson, L. (2012). Brief alcohol screening in a clinical psychiatric population: Special attention needed. Drug and Alcohol Review, 31(4), 538-543. doi:10.1111/j.1465-3362.2011.00333.x

Onocko-Campos, R. T., Passos, E., Palombini, A. L., Santos, D. V. D., Stefanello, S., Gonçalves, L. L. M., ... Borges, L. R. (2013). A gestão autônoma da medicação: Uma intervenção analisadora de serviços em saúde mental [Autonomous Medication Management: An analytical intervention in mental health care services]. Ciência \& Saúde Coletiva, 18(10), 2889-2898. doi:10.1590/S1413-81232013001000013

Ostacher, M. J., Perlis, R. H., Nierenberg, A. A., Calabrese, J., Stange, J. P., Salloum, I., ... Sachs, G. S. (2010). Impact of substance use disorders on recovery from episodes of depression in bipolar disorder patients: Prospective data from the Systematic Treatment Enhancement Program for Bipolar Disorder (STEPBD). American Journal of Psychiatry, 167(3), 289-297. doi:10.1176/appi.ajp.2009.09020299

Pillon, S. C., \& Luis, M. A. V. (2004). Modelos explicativos para o uso de álcool e drogas e a prática da enfermagem [Explanatory models for alcohol and drugs use and the nursing practice]. Revista Latino-Americana de Enfermagem, 12(4), 676-682. doi:10.1590/S0104-11692004000400014

Proal, A. C., Fleming, J., Galvez-Buccollini, J. A., \& Delisi, L. E. (2014). A controlled family study of cannabis users with and without psychosis. Schizophrenia Research, 152(1), 283-288. doi:10.1016/j.schres.2013.11.014
Raitakari, S., Günther, K., Juhila, K., \& Saario, S. (2013). Causal accounts as a consequential device in categorizing mental health and substance abuse problems. Communication and Medicine, 10(3), 237-248.

Ronzani, T. M., Noto, A. R., \& Silveira, P. S. (2014). Reduzindo o estigma entre usuários de drogas: Guia para profissionais e gestores. Juiz de Fora, MG: Editora UFJF.

Schlosser, A. V., \& Hoffer, L. D. (2012). The psychotropic self/imaginary: Subjectivity and psychopharmaceutical use among heroin users with co-occurring mental illness. Culture, Medicine and Psychiatry, 36(1), 26-50. doi:10.1007/s11013-011-9244-9

Schuckit, M. A. (2006). Comorbidity between substance use disorders and psychiatric conditions. Addiction, 101(Suppl. 1), 76-88. doi:10.1111/j.1360-0443.2006.01592.x

Silva, C. R., Kolling, N. M., Carvalho, J. C. N., Cunha, S. M., \& Kristensen, C. H. (2009). Comorbidade psiquiátrica em dependentes de cocaína/crack e alcoolistas: Um estudo exploratório [Psychiatric comorbidity on cocaine/ crack-dependent and alcoholics: An exploratory study]. Aletheia, (30), 101-112.

Szerman, N., Vega, P., Grau-López, L., Barral, C., BasurteVillamor, I., Mesías, B., . . . Roncero, C. (2014). Dual diagnosis resource needs in Spain: A national survey of professionals. Journal of Dual Diagnosis. 10(2), 84-90. doi:10.1080/15504263.2014.906195

Van Boekel, L. C., Brouwers, E. P., van Weeghel, J., \& Garretsen, H. F. (2013). Stigma among health professionals towards patients with substance use disorders and its consequences for healthcare delivery: Systematic review. Drug and Alcohol Dependence, 131(1-2), 23-35. doi:10.1016/j.drugalcdep.2013.02.018

Vieira, F. S. (2016). Consumo de drogas entre pessoas em sofrimento psíquico: Sentidos significados e percursos [Drug use among psychological suffering persons: Senses, meanings and pathways] (Doctoral dissertation). Retrieved from http:/www.teses.usp.br/teses/disponiveis/59/ 59141/tde-20092017-142456/pt-br.php

Vieira, F. S., Caldana, R. H. L., \& Corradi-Webster, C. M. (2013). Relatos de auxiliares de enfermagem psiquiátricos sobre suas práticas e sobre pessoas internadas por uso compulsivo de substâncias psicoativas [Psychiatric nurse professionals reports on their practice and on compulsive psychoactive substance use inpatients]. Saúde \& Transformação Social,4(2), 139-148. Retrieved from http://www.redalyc.org/articulo.oa?id=265328844016

Williamson, A. E., Johnson, P. C. D., Mullen, K., \& Wilson, P. (2012). The disappearance of the "revolving door" patient in Scottish general practice: Successful policies. $B M C$ Family Practice, 13, 95. doi:10.1186/1471-2296-13-95 
Eduardo Augusto Leão holds a M.Sc. from the Faculdade de Filosofia, Ciências e Letras de Ribeirão Preto, Universidade de São Paulo, Ribeirão Preto-SP, Brazil.

Clarissa Mendonça Corradi-Webster is a Professor from the Faculdade de Filosofia, Ciências e Letras de Ribeirão Preto, Universidade de São Paulo, Ribeirão Preto-SP, Brazil

Received: Mar. 23, 2017

1st Revision: Sep. 20, 2017

Approved: Oct. 17, 2017

How to cite this article:

Leão, E. A., \& Corradi-Webster, C. M. (2018). Drug use by individuals under psychiatric treatment: Professional's perception and management. Paidéia (Ribeirão Preto), 28,e2821.doi:http://dx.doi.org/10.1590/1982-4327e2821 